\title{
Latest on the vultures introduced to the Cevennes
}

\section{Peter Mundy}

Department of Forest Resources and Wildlife Management, National University of Science and Technology, Bulawayo, Zimbabwe

mundy@gatorzw.com

http://dx.doi.org/10.4314/vulnew.v70i1.4

Since 1980, the then Fonds particularly we got some gratuitous d'Intervention pour les Rapaces has and splendid information from the been working on the re-introduction man at reception in the Maison.

of the Eurasian Griffon (named in Europe as the Griffon Vulture) Gyps fulvus into the south of France. Specifically the birds were released into the gorges de la Jonte, which river forms the boundary between the Parc National des Cévennes to the north, and the Parc Natural Régional des Grands Causses to the south. Along the road running eastwards from the confluence of the Jonte with the Tarn (at le Rozier), the project built an impressive Belvédère des vautours, more recently known as the Maison des vautours. In fact the building is formidable! I was fortunate to first visit it with the 1999 conference held in the area.

Then just recently, in June 2015, I was again fortunate to visit the place. Yes, there were many griffons flying over the gorges, but more

(i) Griffons - 60 were released from 1981 to 1986 . There are now more than 1200 in the area, including 498 pairs in 2015.

(ii) Cinereous Vulture Aegypius monachus, usually called Black Vulture in Europe - 53 were released from 1992 to 2004. There are now 100 in the area, including 21 pairs.

(iii) Egyptian Vulture Neophron percnopterus - a few birds were seen each year from 1986, which latterly were six to eight birds, including two pairs. No birds have been released, they 'migrate' to here of their own accord every year. So far only one or two youngsters have been produced each year. 
(iv) Bearded Vulture Gypaetus All four species of European vultures barbatus - two juveniles are released in one place in southern France each year, starting in 2012. merveilleux!

This news came as a great surprise to me, as I thought that the cliffs of the gorges of the Jonte and Tarn were not 'rugged' enough for this species. Will it be able to use its quartering method of foraging on the I thank Mr Jim Powell for driving me to the area, and back. Also I thank M. Raphaël Néouze at LPO in Peyreleau for correcting the information that I collected.

grassy plateaux above? 